Southern Illinois University Edwardsville SPARK

SIUE Faculty Research, Scholarship, and Creative Activity

Spring 2018

\title{
Applying Spatial Literacy to Transform Library Space: A Selected Literature Review
}

\author{
Juliet M. Gray \\ Southern Illinois University at Edwardsville, jkerico@siue.edu \\ Melissa Burel \\ AlabamaA\&M University, melissa.burel@aamu.edu \\ Marlee Graser \\ Southern Illinois University Edwardsville, magrase@siue.edu \\ Karen Gallacci \\ Southern Illinois University Edwardsville, kgallac@siue.edu
}

Follow this and additional works at: https://spark.siue.edu/siue_fac

Part of the Geographic Information Sciences Commons, and the Library and Information Science Commons

\section{Recommended Citation}

Gray, Juliet M.; Burel, Melissa; Graser, Marlee; and Gallacci, Karen, "Applying Spatial Literacy to Transform Library Space: A Selected Literature Review" (2018). SIUE Faculty Research, Scholarship, and Creative Activity. 87.

https://spark.siue.edu/siue_fac/87

This Article is brought to you for free and open access by SPARK. It has been accepted for inclusion in SIUE Faculty Research, Scholarship, and Creative Activity by an authorized administrator of SPARK. For more information, please contact magrase@siue.edu. 


\title{
Applying spatial literacy to transform library space: A selected literature review
}

\begin{abstract}
Purpose - The purpose of this research paper is to review a selection of articles and books that highlight aspects of spatial theory and literacy from various disciplinary perspectives, along with a review of library space studies.

Design/methodology/approach - This study reviews library literature published between 2010 to 2017 that utilizes spatial literacy and its related tools. The authors searched full text in two databases, a library specific database, Library, Information Science and Technology Abstracts (LISTA), and in a multi-disciplinary database SCOPUS. The article records were analyzed to find primary research studies, published between 2010 and 2017, which study patron use of library space using various single and hybrid methodologies.
\end{abstract}

Findings - The findings of the literature reveal that of the 26 studies reviewed, 23 have a descriptive research question, three have a relational research question, and zero have a causal research question. Based on the analysis of the research methodologies employed, there is more that can be done in support of a librarian's research efforts as well as the arenas in which research is conducted.

Practical implications - These findings highlight ways in which LIS researchers and those who educate them can broaden collective knowledge within the profession regarding spatial theory, literacy, and applicable research methodologies for studying and innovating library space.

Originality/value - Current and best practices for designing library space studies that employ spatial literacy to collect and analyze data are identified along with a discussion of future directions for LIS researchers to better assess space and communicate the value of innovated physical space in libraries.

Keywords - GIS, Spatial literacy, Spatial theory, Space studies, Library buildings

Paper Type Literature review

\section{Introduction}

Within geographical studies, spatial literacy is the standard mode of thinking. Turning to scholars who apply spatial literacy skills and tools in their research is helpful in establishing core competencies for researchers who aim to become more literate within their respective fields. In addition to practical skills, an understanding of theory and methodology is also helpful for establishing context. Although the definition of social geography as a sub-discipline of geography has changed over the past century, Del Casino (2009) currently defines it as 
a constellation of theoretical and methodological approaches that converge and diverge in an attempt to understand and explain the spatial organization of what we could think of broadly as difference and inequality (p. 15).

Understanding the basic elements of spatial literacy and social geography provides justification for library initiatives that aim to transform space. an endeavor that is most successful when it is based on the patterns of behavior or preferences of those who actually use library space and not on the prescriptions of tradition, professional preferences, or commercial vendor recommendations.

The trends of the past 20 years have made librarians acutely aware that the needs and preferences of users are constantly in flux. Concepts of spatial literacy and the research design methods that support such inquiry can create powerful methods for rich, ongoing assessment in a fluid environment. If the patron is the main subject for study, it follows that applying research methodologies to adequately study this population is the key to delivering truly innovative $21^{\text {st }}$ century experiences and services within libraries. Whether LIS researchers are attempting to make changes based on preliminary studies of users, or aiming to validate physical changes after renovation, utilizing methods used by geographers, architects, and urban planning professionals are the key to assessing and transforming the use of library space.

Increased exposure to and improved grounding in spatial theory and literacy, along with complementary research methodologies, will enable researchers to contribute much needed data to re-envision and invigorate physical sites of learning and possibly even the process of learning itself. Although concerns such as increasing funding and improving patron buy-in might often drive space inquiries at their outset, for libraries in particular, many user studies or renovation projects seek to innovate space for the sake of improved learning outcomes. LIS research that contributes to this ongoing conversation not only improves libraries, it provides an opportunity to participate in interdisciplinary scholarly exchange that impacts learners and institutions as a whole.

\section{Background/Bibliographic Analysis}

In their article "Utilizing geographic information systems (GIS) in library research," Bishop and Mandel (2010) explore the body of library research that used GIS tools to measure and analyze library services. As a review designed to explore the integration of geographical spatial literacies within library research, Bishop and Mandel also speak to the practical implications of this methodology and directions that future research in the area of library spatial research design might be focused. This article aims to address these future directions by exploring and compiling library research studies that employ spatial literacies in their design and include methodologies intended to study patron use, preference, and needs. Additionally, this selected review expands on Bishop and Mandel's work by extending its scope beyond studies that utilize GIS tools exclusively to include studies on user populations and activities within library spaces and aims to review the breadth of research that has embedded spatial literacy in research design methods. 
A bibliographic analysis of the studies selected for review, all published between 2010 and 2017, reveals several resources that have impacted either the theory or practice of multiple studies. Applegate (2009), referenced in eight studies, examines the use of specific, differently configured areas within the library. This longitudinal study tracks usage throughout the week, semester, and academic year, and compares library use to simultaneous non-library area use on campus. Applegate stresses that an "effective library is one that addresses the entire spectrum of student needs" (p. 345). Bennett (2007), also referenced in eight studies, contains an appeal to those designing library space studies to question the "character of the learning we want to happen in the space" (p. 14). He suggests that future researchers attempt to answer questions about the differences between physical and virtual space, how we can design spaces to encourage productivity and student/teacher exchange outside of the classroom, the best ratio of quiet to collaborative study space, and how space can enrich educational experiences.

The publication edited by Foster and Gibbons (2007), referenced in thirteen studies, focuses on support of the university's educational mission by researching students and professors. The study stresses the importance of knowing students' habits, the academic work they are assigned, how they write research papers, and faculty expectations of student research, along with the most useful facilities and services to address these issues. Foster and Gibbons also explore a comparison of library spaces to other on-campus environments.

Given and Leckie (2003), referenced in eight articles, focuses on recording social and informational activities. Their study details spatial analysis techniques used by geographers, psychologists, and anthropologists that can be repurposed to map the physical layout of libraries and to record the activities of users. Given and Leckie specifically highlight the space-time technique, which tracks what users did and at what time, and cognitive mapping, which is a multi-disciplinary mental mapping approach that provides insight into how individuals perceive physical spaces. Additionally, the text cites the importance of room geography, referring to how users distribute themselves to maintain personal space and privacy, and person-environmental psychology in planning the data points collected in space studies.

\section{Spatial Theory}

Throughout the published literature, from more theoretical pieces to primary space studies, the most frequently cited theorist is Henri Lefebvre for his Production of Space (1991). This text, situated within sociological discourse, forms a solid foundation from which cross-disciplinary research related to spatial theory has continued to evolve. A review of the research within Library and Information Science (LIS), reveals that the application of spatial theory appears to be relatively new.

In Leckie, Given, and Buschman's textbook Critical Theory for Library and Information Science (2010), a chapter is dedicated to the discussion of Lefebvre's groundbreaking and influential theory of space, focusing on his three-part framework for defining the "science of space" through a "conceptual triad" which is delineated by three aspects of social space: spatial practice, representations of space, and representational spaces (p. 227). The authors distill these into the following: "spatial practice includes not only the ongoing development of the built environment (the physical), but also how we 
perceive it (the mental), and the ways in which it shapes our lives (the social), all of which forms a type of spatialized practice" (p. 228). An understanding of these three concepts is helpful for providing a structure, what Leckie and Given call a "Lefebvrian theoretical lens," for researchers (p. 235). Lefebrve's theory provides a cohesive and multidimensional theoretical approach for LIS researchers attempting to understand how users experience space relative to their goals, to investigate how users incorporate space into their broader social lives, and, ultimately, to use that information to innovate the appearance of their physical buildings. It could be argued that any space study that ignores any one of Lefebrve's three core concepts might be providing an incomplete picture of the forces at work within that space.

In a study that could provide insight for LIS researchers, educational scholars Gregory, Hopwood and Boud apply Lefebvre's spatial theory to a healthcare setting, positing that although "spatial theory is not an explicit theory of learning, it enables us to illuminate things not otherwise noticeable to help understand the interface between everyday practice and learning" (p. 200). Their findings reveal that Lefebvre's tri-partite framework enables researchers to "move beyond simplistic notions of physical or objective space, which treat space as a container for practices...instead a complex scene unravels in which conceptions, practices, and the lived experience of space inter-relate, support and perhaps 'bump into' each other” (p. 204). Gregory, Hopwood and Boud's findings support the notion that spatial theory applied in a multitude of educational settings has the ability to encourage a more nuanced understanding of what motivates learners within a certain physical environment, revealing that learning is relational and occurs with fluidity in and around the constructed physical and professional boundaries that we have traditionally perceived as solid and hierarchical.

In addition to citing Lefebvre, Harrop and Turpin (2013) apply Fleming's theoretical approach from the The Art of Placemaking along with theories of learning and architecture to study informal "space behaviors" in an academic library setting. Fleming, a scholar within the discipline of urban planning, uses the term placemaking to emphasize the study of an individual's experiences while occupying a specific place, similar to Lefebvre's concept of "lived space." The authors assert that in order to construct successful informal learning spaces, LIS researchers must consider all three theories and their relationship to one another (p. 61). As the space preferences and learning needs of individuals evolve, employing interdisciplinary theories, such as the theories of learning, architecture, and placemaking, broadens the understanding of how libraries need to innovate in order to provide better spaces for learning.

Geographers provide numerous pragmatic approaches for defining and developing spatial literacy skills. Goodchild and Janelle (2010) extend the application of these approaches to the social sciences and humanities, which is particularly helpful for professions, such as LIS, that may lack standard formal training in these skills. They assert that students need to be better trained "in the challenges of working with phenomena embedded in space and time," and that "applying critical thinking to research in a range of disciplines" is needed if students "are to develop as leaders of a spatially enabled scholarship" (p. 10). Following from the work of Goodchild and Janelle, geographers Benarz and Kemp (2011) make a case for improving spatial literacy by issuing a "Grand Challenge" that proposes "a careful and empirically based description of spatial literacy across many domains," and encourages developing a "research 
agenda...focus[ed] on how expertise in spatial thinking and reasoning develops." (p. 21).

Branch (2014) addresses the link between spatial literacy, libraries, and "nextgeneration education," by encouraging the expansion of "GIS data-supporting personnel" as a service to patrons (p. 110). While he doesn't correlate this initiative to enhancing the ability of librarians to reflexively study and analyze the uses of library spaces, his acknowledgment of a deficit of formal training in spatial literacy within LIS education reveals related concerns. As librarians become better trained in spatial literacy, the benefits toward next-generation education are two-fold: increased ability to provide data services to patrons, and enhanced knowledge and utilization of those skills to renovate and enhance learning spaces for patrons.

In Literacy Theories for the Digital Age (2016), Socio-spatial Literacy is one of the "lenses" or new paradigms Mills defines through a review of the work of literacy theory scholars. Revisiting the foundational ideas of Lefebvre, Mills reminds readers that "space and literacy practices, and the organization and meaning of those literacy spaces, are socially constructed." As such, an understanding of the inequities that are the byproduct of how "power and space interact with literacy practices" is central to developing strategies to combat marginalization and disadvantage within certain geographies that fail to provide neutral learning spaces (p. 93).

Henry Myerberg's introduction to Creating the High-functioning Library Space (Deyrup, Marta Mestrovic, eds. 2017) provides a pragmatic application of three interrelated qualities of space: visibility, flexibility, and density. Visibility refers to the way in which sight line addresses acoustic, climatic, and security concerns. Flexibility involves providing space that can be adapted to different user needs, focusing on making all library space multi-purpose space. Density is concerned with how people are drawn to busy places, and how these dense locations can conserve energy and cost as well as provide a welcoming social atmosphere (p. xi-xv). Although spatial theory is not referenced within this text, it provides practical guidance to LIS researchers for studying and transforming space, referring to many concepts of spatial literacy across multiple disciplines from various authors' points of view.

\section{Methodology}

This study was designed to selectively review foundational and evolving theories of spatial literacy applicable to the field of LIS, and to review the research methodologies of a selection of primary research studies, published between 2010 and 2017, that analyze the use of library space. As a continuation of some themes raised in Bishop and Mandel (2010), which called for "additional research [to] expand on the two research areas... analyzing service area populations and managing facilities," this selected review was designed to examine current research methodologies applied to spatial studies in libraries. Bishop and Mandel note that "[w]ith regard to managing facilities, even less research utilizing GIS seems to occur...providing even more opportunities for future research agendas,' and suggesting that "best practices for methodology could be established" going forward (p. 542-543).

To identify studies, we searched full text for (studies OR space studies) or (space study) in one library specific database, Library, Information Science and Technology Abstracts (LISTA), and for spatial and (study OR research OR assessment) and (libraries 
OR library) in a multi-disciplinary database SCOPUS. The search results in LISTA, limited by date range, returned 298 records and the search results in SCOPUS, limited by date range and the subject area of Social Sciences, returned 191 records. Additionally, LISTA was searched for articles and textbooks, published within the same time-frame, with the terms (space OR spatial) AND theory AND (buildings OR architecture), returning 63 records.

The records were analyzed to find primary research studies utilizing spatial research methodologies in order to assess use or renovate/innovate spaces within library buildings. Much of the selected literature dealt with providing spatial data services to patrons, which was outside the scope of this review. Forty research studies, case studies, and review articles were identified to be within the scope of this review. Of those resources, 28 articles from 2010-2017 utilized methodologies such as GIS, visual traffic sweeps, patron interviews and visualization techniques. Two of these articles were case studies without a formal methodology and are not included in the critique provided here. Ultimately, 26 articles were identified as studies that had utilized spatial theory in their quantitative, qualitative, and hybrid methodologies.

\section{Findings}

Within a selected review of research studies, it is valuable to get a sense of the types of methodologies being used. With few exceptions, researchers are not choosing one specific methodology, but are overwhelmingly opting to develop research methodologies that include many different ways to collect data in order to get a clearer understanding of student perceptions and spatial use. The most common methods are examined below, including the use of surveys, observations, mapping and GIS technologies, photo elicitations, and interviews.

Only two studies, Cha and Kim (2015) and Yoo-Lee, Heon Lee, and Velez (2013), utilized surveys exclusively to gather data on spatial use. In the case of Cha and Kim (2015), the survey was given out in two parts, the first to gather demographic information and indicate the purpose of the student's visit to the library, and the second to gather quantifiable data on the importance of eighteen defined space characteristics. Yoo-Lee et al. distributed a survey to explore perceptions of the library and also asked open ended questions about communal space within the library. Both of these types of surveys successfully gathered data that highlighted themes of student use and the attributes and design that characterize a successful library space.

While only two studies used surveys exclusively to gather data, surveys played a major role in baseline data collection for many of the studies employing a mixed methods approach. Of the eighteen studies that used mixed methodologies, twelve of them included the use of a survey. The method of distribution of five studies was in-person only or paper only ((DeClerq \& Cranz (2014), Imamoglu \& Gurel (2016), Khoo, Rozaklis et al (2016), Lux, Snyder, \& Boff (2016), and May \& Swabey (2015)). Four studies included the option of taking the survey online or in-person (Dominguez (2016), Holder \& Lange (2014), Montgomery (2014), and Webb, Schaller, \& Hunley (2008)). The survey in one study was distributed online only (Hall \& Kapa (2015). Interestingly, May and Swabey found that for their multi-site study, participation rates were much higher for surveys distributed in paper format rather than online, and therefore chose to 
change their distribution model to paper-only for all study sites after the first (p. 774). The purpose of the surveys also varied greatly and included determining the success of recent library renovations ((Fox \& Doshi (2013) and Imamoglu and Gurel (2016)) and quantifying library use patterns ((Hall \& Kapa (2015), Lux et al. (2016), and May $\&$ Swabey (2015)). The most common purpose for distributing surveys was to collect quantifiable information on spatial preferences and satisfaction. While surveys, by nature, gather quantitative data, eight of the studies included open ended questions that could be analyzed qualitatively to discern nuances and common themes that might be missed in a more structured questionnaire.

Similarly, researchers utilized observations in many forms to gather data on student use of library space. Seven research studies used observations exclusively to collect data and twelve of the mixed methods studies included data collected using observations. Of the nineteen total studies that implemented observational methods, twelve of them used seating or visual traffic sweeps conducted at regular intervals during a specified time frame. The majority of these studies used tally marks during physical walkthroughs of the building, although one variance, Webb et al. (2008), recorded the headcounts in each zone of their library using video equipment and then tallied them at a later date. Dominguez (2016), Holder and Lange (2014), Lux et al. (2016), and Princeton Theological Seminary Library (2014) opted to use software or web-based applications, such as Google Forms, QuickTapSurvey, or Suma, to record seating sweep data during the walkthroughs. Additionally, Thompson (2015) provides an overview and comparison of two mobile applications used for tracking library space use during observations. While most of the studies employing observations used them to gather purely quantifiable data on usage patterns and preferences in each library space, Bedwell \& Banks (2013) used opportunistic participant observations in which members of the student community recorded qualitative information on their own library use as well as their observations of students around them. DeClercq and Cranz (2014), Di Marino and Lapintie (2015), Dominguez (2016)(2016), and Harrop and Turpin (2013) used observations to document both quantitative and qualitative information. Specifically, Dominguez used observational notes with photo diaries taken by the researchers to provide more context to the headcounts that were also collected.

Of the 26 studies analyzed, eight used some form of mapping or use of GIS technologies to collect and analyze data. Bedwell and Banks (2013), although conducting a qualitative analysis, plotted patterns of use on floor plans in order to identify trends. This is similar to the quantitative tracking methods of Gullikson and Meyer (2016) in which headcounts were recorded on detailed floor plans of the building. Xia (2005) also recorded headcounts and furniture use in this way and his article provides a good overview of the ways in which GIS tools can enhance spatial analysis. Khoo et al. (2016) and Given and Archibald (2015) used GIS tools to analyze their headcount data by uploading data spreadsheets into GIS software in order to visualize and manipulate the data. Mandel (2010) gathered data specifically on patron entry routes and used ArcMap to trace and analyze routes. In addition to the use of GIS tools to record and analyze data, mapping exercises were used to gather information from users. In lieu of asking structured questions marked according to a rating scale, Khoo et al. (2016) conducted a survey that required students to annotate maps and indicate their preferences spatially. In two separate exercises used to gather spatial data from participants, Hobbs 
and Klare (2010) used campus maps to prompt users to record the time and location of their activities at the university and also invited students to sketch their ideal space. Similar to this, Treadwell, Binder, and Tagge (2012) utilize exercises in order to understand students' perceptions of library space as well as their preferences. Their study used cognitive mapping, in which students drew a map of the library from memory, as well as design workshops, in which students reflected on and designed their ideal space.

Treadwell et al. (2012) also used photo elicitation with follow up interviews to supplement their understanding of student spatial preferences, similar to methods found in DeClercq and Cranz (2014), Hobbs and Klare (2010), and Harrop and Turpin (2013). While all of these authors used photo elicitation with follow up interviews as part of a mixed methodology, Newcomer and Harriman (2016) utilized photo elicitation and follow up interviews exclusively in their study of a conservatory library. In other studies this methodology was used for the same purpose as focus groups and one-on-one interviews in which researchers were able to develop contextual information around the quantitative and spatial data also being collected. As Treadwell et al. state, "the most nuanced comments about library space came not from any of the specific methodologies relating to space which we employed, but from the general interviews" (p. 138). Qualitative data gathered from focus groups or one-on-one interviews were used in the methodologies of Di Marino and Lapintie (2015), Hall and Kapa (2015), Montgomery (2014), Treadwell et al. and DeClercq and Cranz.With the exception of the study conducted by Bailin (2011), who used structured interviews exclusively to gather quantitative and qualitative data, interviews were overwhelmingly used in mixed methodology approaches.

\section{Critique}

Assessment of library space is becoming an important topic as libraries are transitioning from a place for resources to a place for space. With resources moving to the digital format, libraries are downsizing physical collections, allowing for the utilization of more physical space in the library. While this article is a selective review of the space literature in libraries, a few trends are observable. Some of these trends involve common types of research questions, those who are conducting the research, the types of libraries involved in the process, and some challenges within the research process.

. Within the field of research, there are three types of research questions: descriptive, relational, and causal. The purpose of the descriptive research question is to observe and catalog data in order to broaden one's understanding about an issue (Steinberg and Steinberg, 2015). Relational research is designed to show the relationship between two or more variables, and causation research is designed to prove that a variable causes an effect to one other variable or multiple variables. When one begins researching a topic that is unfamiliar, it is common to start with a descriptive research question to gain a general understanding and context about the subject. Once a descriptive study has been analyzed, a researcher may go on to create a research question to investigate the relationship between variables observed in the descriptive study. If carried out successfully, the researcher may then choose to determine causation between variables to determine cause and effect. Or if a researcher has a deep understanding regarding a topic, she may go directly to causation research. These different types of 
research gradually become more challenging, with a causal study being the most arduous of the three.

Of the 26 studies reviewed here, 23 have a descriptive research question, three have a relational research question, and zero have a causal research question. A few conclusions can be inferred from this data. Since so many studies are descriptive or exploratory in nature, it is logical to assert that most libraries are just beginning to investigate their spaces. Of course, librarians are always observing patron behavior and gathering anecdotal evidence, but in terms of creating a formal space study, this appears to be a relatively new topic in many libraries. The inclusion of relational research also shows that some institutions have conducted descriptive work and are taking the research one step further to address more specific phenomena. In this review, relational research questions included pre- and post-testing of changes, either renovations or furniture adjustments, made within the library. The absence of studies that show causation could be contributed to a variety of factors. Since a researcher needs a deep understanding of the situation of space usage in their library to develop theories about possible variables and their influences, it could reflect the newness of formal library space studies. Since causal studies are also the most sophisticated in nature, their absence may be due to a lack of training. In order to show causation, a researcher has to know how to set up a study to show causation and then be able to control for other possible influencing factors, which involves higher-level research skills. One could argue that the absence of causal studies in this review is because causation is impossible to determine in studies utilizing qualitative methods. However, this is an older perspective, one Maxwell (2004, p. 247) rebukes in his article, Using Qualitative Methods for Causal Explanation, citing a realist philosophy on science which asserts that "...causation is compatible with, and supports, all the essential characteristics of qualitative research..."

Another trend within these articles is the profile of the researchers involved. Fifteen studies were conducted by lone or multiple librarians or professors in library science, eight were conducted by librarians with others on campus such as sociology or architecture faculty and/or their classes, and three were conducted by outside consultants or departments. Studies conducted in teams or by outside consultants tended to collect more robust data and were more successful in distilling results. Many of these studies also utilized mixed-methods. Multiple methods require knowledge in various areas of research, a greater investment of time to conduct the study, the data is more robust and nuanced, and reporting the findings accurately requires different standards for each type of method. These additional requirements in time and application make it challenging for one person to accomplish successfully and in a useful timeframe.

One of the reviewed studies included librarians and an undergraduate architecture class to investigate specific library space questions based on a post-occupancy survey. Each team of students addressed their assigned question, and in many cases, used multiple methods per question. This collaboration served as a pedagogical tool for the students to learn social science research methods and provided large amounts of highquality data for the library (DeClercq and Cranz, 2014). This type of in-depth data collection is not manageable for a lone librarian. While this may seem like an obvious observation, it is easy for library staff to have tunnel vision and fail to consider what other faculty or departments can bring to the research. 
The institution at which a study is conducted has implications for the generalization of results. Of the 26 studies reviewed, 24 were conducted at one or more academic institutions or conservatories, one was conducted at a public library, and one was conducted in both academic and public library settings. The possible reasons for the shortage of research conducted at public libraries vary. Many academic librarians are expected to conduct research, especially when in a tenure track position; therefore, more research emanating from academia is logical. Also given that many librarians at public libraries are more likely to be part time and covering multiple positions, undertaking time-consuming and rigorous research can be unrealistic. Another possible factor for lower amounts of studies conducted at public institutions could be a bias of this review resulting from the focus of consulted publications, which could have a more academic leaning. A systemic review of the literature on library space would clarify this possible bias.

Sampling methods and survey design must be addressed. In a few cases, researchers utilized a convenience sample in order to gather data. While this sample method is useful for discovering possible issues, a researcher cannot expect the percentages or emphasis of those issues to be accurate (Bernard, 2013). When using this sample type, it is important to list the limitations. Many of the studies did an excellent job of mentioning these limitations either in the Limitations, Data Collection, or Participants sections, however some did not include this information. Along with omissions of the limitations of sampling methods, there are instances where researchers did not mention how the population was sampled at all, which is important information for determining potential bias within the data.

In addition to understanding sampling standards, researchers must also adhere to best practices of implementing and reporting survey data.

. Numerous studies omitted response and/or completion rates, which call into question how applicable the results are to the whole population. One hundred survey respondents for an institution of 200 people (50\% response rate) has a different significance than for an institution of 2,000 (5\% response rate). May and Swabey (2015) provide an excellent table of information in their article that includes the institution's FTE, number of seats, along with other useful information of the five participating libraries. This is accompanied by a thorough description in their method section of their sampling methods and survey response rates. There are instances that a response rate cannot be provided due to a lack of a sampling frame, especially when librarians are surveying only library patrons that utilize a specific space. While surveys are typically used to gather quantitative data, they can be used for qualitative data collection. If a researcher conducts a survey with a participant in-person, there is an opportunity for clarification with the individual or group. Without this opportunity for probing qualitative responses, misinformation and unclear responses are common. Since it is important for a researcher to gather accurate information, it may be best to avoid a qualitative survey and to instead select a better-suited methodology.

Some studies in the selected review confused conducting research from a grounded theory approach verses conducting research from an inductive approach. The grounded theory methodology (which is also a data-analysis strategy) involves observation without any preconceived ideas or hypothesis, analyzing the data for thematic categories, and then generating a theory, which is ultimately the purpose and 
emphasis. The creators of grounded theory define it as "the discovery of theory from data" (Glaser and Strauss, 2000, p. 1). While this method is inductive (research without a preconceived hypothesis) the final product is a theory based on the links between themes with publications utilizing exemplars (Steinberg and Steinberg, 2015). Ultimately it is important to remember that although all grounded theory is inductive, not all inductive methods are grounded theory.

\section{Applications}

Library researchers are working more and more to use new methodologies to gather data to address important questions that relate to library space. Based on this selected review, more must be done in support of a librarian's research efforts as well as the arenas in which research is conducted.

While it is outside the scope of this article to assess the instruction provided to students in the MLIS curriculum, every new librarian enters the field of librarianship with different levels of knowledge and experience in how to conduct research. All librarians need a standard minimum amount of information to be able to conduct research and communicate findings appropriately. Research that is exploratory in nature is the easiest to perform and can have a large impact in library practice. If, as a professional body, the goal of library research is to show causation between library use and other factors such as GPAs, student success, student retention, community involvement, or patron well-being to name a few then librarians need to have the training to know what is needed to show causation between different variables. While librarians can partner with those that have more training, they need to be able to recognize situations where this is possible. In another effort to raise the level of the professional literature, librarians need more training not only on conducting research, but also on how to report on different methodologies. should be provided. While small mistakes in research are admissible, too many inconsistencies within a study can call the whole work into question, causing the reader to doubt the study's validity and reliability. This kind of training can come in many forms starting with the MLIS and continuing with opportunities for professional development.

Along with educational opportunities, librarians conducting research require support in other ways. This includes time to conduct the research, financial assistance, as well as mentorship. One of the authors of a study mentioned the low response rate for a survey saying, "...due to the limited budget for this project, no incentives to complete the survey was offered. The lack of incentive may have further reduced the number of respondents..." (Hall, 2015, p. 5). In the same article, the researcher mentioned a lack of time to include an additional ethnographic method, which would have enhanced the study.

An approach that can assist librarians to mitigate any lack of understanding, time, and resources are partnerships. This literature review has shown that by engaging students, faculty, or other professionals within research fields, more data can be generated using a larger variety of methods. While mixed-methods approaches to research are valuable in generating holistic understanding, this type of data gathering is impractical for one person who has other responsibilities within the library. A team comprised of experts in qualitative and quantitative methods can ensure that both parts of a study are done well with high levels of reliability and validity. With more people involved, it is possible to complete a study in a timely manner without overloading an 
individual. Even a single methodology can be overwhelming for one person, as expressed by Dominguez in her article where she describes conducting seating sweeps, "However, because the study was conducted by a single researcher, sweep data were limited to the researcher's regularly scheduled hours. In future, a team approach may prove more effective in gathering data..." (Dominguez, 2016, p. 327). While working in teams has its own challenges and is not the panacea for the obstacles librarians face conducting research, the possible outcomes are worth the effort.

Finally, space research needs to be conducted in more public. Librarians, no matter their context, need data in order to be advocates for themselves, their patrons, and to demonstrate their institution's value. This is especially important in times of fiscal uncertainty, but is also valuable in times of growth, when a case needs to be made for fiscal allocation. Many of these space studies were conducted around renovations to determine patron needs or their response to enhanced spaces. In fair weather or foul, librarians need data to make informed decisions.

\section{Future Implications}

Looking forward, within LIS research it is likely we will see new or advanced technology used in library spatial research, such as Indiana University's use of stopmotion video uploaded to heat-mapping software (Dallis, 2016) and mobile apps like CloudOn and Counter+ at California State (Thompson, 2015). Momentum is continuing to build toward finding ways to transform library space into highly innovative learning space. Bennett's book, often cited in the studies reviewed, is a foundational study for this concept. Bennett (2003) calls for greater understanding of learning processes and the importance of applying that understanding to planning library space, asserting that we must "think more like educators and less like service providers" (p.194). He emphasizes the importance of partnerships between academic units, librarians, and technologists in creating innovative learning spaces. Additionally, Turner, Welch, and Reynolds (2013) look extensively at evolving trends toward collaborative environments and learning spaces, stressing that the future of library space is its transformation learning spaces. (2013).

Returning to Mills's overview of socio-spatial literacy in Literacy Theories for the Digital Age (2016) is an opportunity to mine a growing theoretical approach to expand our knowledge and application of spatial literacy within LIS. Using spatial research methods to investigating how recent cultural shifts have altered the user's perceptions of shared learning spaces within libraries can provide a wealth of data that has implications, not only for libraries, but for entire universities.

\section{Conclusion}

The goal of this literature review was to enhance librarians' knowledge of best practices within space assessment for those who have minimal professional training in spatial theory and its complementary research methodologies. Additionally, the hope is that this article will help advocate for increased spatial literacy skills and practices within the profession by highlighting the way that analysis of spatial data can significantly impact efforts to enhance library space, and library services, and student learning. Finally, this review is a call for more data-informed administrative decision-making 
within space assessment. Data-informed decisions unite stakeholders around the common cause of improving library services through methods that communicate respect for the needs and values of patrons and toward the goal of impacting retention and success in all types of libraries. 


\section{Bibliography}

Applegate, R. (2009) "The library is for studying: Student preferences for study space". The Journal of Academic Librarianship, 35 No. 4, pp. 341-346. Available from https://doi/10.1016/j.acalib.2009.04.004

Bailin, K. (2011), "Changes in academic library space: a case Study at the University of New South Wales", Australian Academic \& Research Libraries, Vol. 42 No. 4, pp. 342-359, available at: https://doi.org/10.1080/00048623.2011.10722245

Bednarz, S. and Kemp, K. (2011). Understanding and nurturing spatial literacy. In: International Conference: Spatial Thinking and Geographic Information Sciences. [online] Tokyo: Elsevier, pages. Available at: https://doi:10.1016/j.sbspro.2011.07.004 [6 Oct 2017].

Bedwell, L., and Banks, C. (2013), "Seeing through the eyes of students: Participant observation in an academic library", Partnership: The Canadian Journal of Library and Information Practice and Research, Vol. 8 No. 1, pp. 1-17, available at: http://dx.doi.org/10.21083/partnership.v8i1.2502

Bennett, S. (2003), "Libraries designed for learning", available at: www.clir.org/pubs/reports/pub122/pub122web.pdf (Accessed 17 February 2018)

Bennett, S. (2007), "First questions for designing higher education learning spaces", The Journal of Academic Librarianship, Vol. 33 No.1, pp. 14-26, available at: https://doi.org/10.1016/j.acalib.2006.08.015

Bennett, S. (2008), "The Information or the Learning Commons: Which Will We Have?", The Journal of Academic Librarianship, Vol. 34 No. 3, pp. 183-185, available at: https://doi.org/10.1016/j.acalib.2008.03.001

Bennett, S. (2009), "Libraries and learning: A history of paradigm change", Portal: Libraries and the Academy, Vol. 9 No 2, pp. 181-197, available at: https://muse.jhu.edu/article/262845

Bernard, H.R. (2013), Social Research Methods: Qualitative and Quantitative Approaches, $2^{\text {nd }}$ edn, Sage Publications, California.

Bishop, W.B. and Mandel, L.H. (2010), "Utilizing geographic information systems (GIS) in library research", Library hi tech, Vol. 28 No. 4, pp. 536-547, available at: https://doi.org/10.1108/07378831011096213

Branch, B.D. (2014), "Libraries and Spatial Literacy: Toward Next-Generation Education", College \& Undergraduate Libraries, Vol. 21 No. 1, pp. 109-114. 
Cha, S.H. and Kim, T.W. (2015), "What matters for students' use of physical library space?", The Journal of Academic Librarianship, Vol. 41 No. 3, pp. 274-279, available at: https://doi.org/10.1016/j.acalib.2015.03.014

Dallis, D. (2016), "Scholars and learners: a case study of new library spaces at Indiana University", New Library World, Vol. 117 No. 1/2, pp. 35-48, available at: https://doi.org/10.1108/NLW-04-2015-0023

DeClercq, C. P. and Cranz, G. (2014), “Moving beyond seating-centered learning environments: Opportunities and challenges identified in a POE of a campus library", The Journal of Academic Librarianship, Vol. 40 No. 6, pp. 574-584, available at: https://doi.org/10.1016/j.acalib.2014.08.005

Del Casino, V. (2009), Social Geography: A Critical Introduction, Wiley-Blackwell, Chichester, U.K.

Deyrup, Marta Mestrovic, eds. (2017) Creating the High-functioning Library Space: Expert Advice from Librarians, Architects, And Designers. Libraries Unlimited.

Di Marino, M. and Lapintie, K. (2015), "Libraries as transitory workspaces and spatial incubators", Library \& Information Science Research, Vol. 37 No. 2, pp. 118129, available at: https://doi.org/10.1016/j.lisr.2015.01.001

Dominguez, G. (2016), "Beyond gate counts: seating studies and observations to assess library space usage", New Library World, Vol. 117 No. 5/6, pp. 321-328, available at: https://doi.org/10.1108/NLW-08-2015-0058

Fingerman, S. (2017), "Creating the High-Functioning Library Space: Expert Advice From Librarians, Architects, and Designers", Sci-Tech News, Vol. 71 No. 1, pp. 31-31.

Foster, N. and Gibbons, S. (Eds.) (2007), Studying Students: The Undergraduate Research Project at the University of Rochester, Association of College \& Research Libraries, Chicago, IL.

Fox, R. and Doshi, A. (2013), “Longitudinal assessment of 'user-driven' Library Commons Spaces", Evidence Based Library and Information Practice, Vol. 8 No. 2, pp. 85-95, available at: http://dx.doi.org/10.18438/B8761C

Given, L. M. and Archibald, H. (2015), "Visual traffic sweeps (VTS): A research method for mapping user activities in the library space", Library \& Information Science Research, Vol. 37 No. 2, pp. 100-108, available at: https://doi.org/10.1016/j.lisr.2015.02.005

Given, L. M. and Leckie, G. J. (2003), "'Sweeping' the library: Mapping the social activity space of the public library”, Library \& Information Science Research, 
Vol. 25 No. 4, pp. 365-385, available at: https://doi.org/10.1016/S07408188(03)00049-5

Glaser, B. and Strauss, S. (2000), The Discovery of Grounded Theory: Strategies for Qualitative Research, Routledge, Oxon.

Goodchild, M. (2006), "The fourth R? Rethinking GIS education", ArcNews, Vol. Fall, pp. 1-5.

Goodchild, M.F. and Janelle, D.G. (2010), "Toward critical spatial thinking in the social sciences and humanities", GeoJournal, Vol. 75 No. 3, pp. 3-13.

Gregory, L.R., Hopwood, N. and Boud, D. (2014), "Interprofessional learning at work: what spatial theory can tell us about workplace learning in an acute care ward", Journal Of Interprofessional Care, Vol. 28 No. 3, pp. 200-205.

Gullikson, S. and Meyer, K. (2016), "Collecting space use data to improve the UX of Library Space", Weave: Journal of Library User Experience, Vol. 1 No. 5, pp. 124, available at: http://dx.doi.org/10.3998/weave.12535642.0001.502

Hall, K. and Kapa, D. (2015), "Silent and independent: Student use of academic library study Space", Partnership: The Canadian Journal of Library and Information Practice and Research, Vol. 10 No.1, pp. 1-38, available at: http://dx.doi.org/10.21083/partnership.v10i1.3338

Harrop, D. and Turpin, B. (2013), “A study exploring learners' informal learning space behaviors, attitudes, and preferences", New Review of Academic Librarianship, Vol. 19 No. 1, pp. 58-77, available at: https://doi.org/10.1080/13614533.2013.740961

Hobbs, K. and Klare, D. (2010), "User driven design: Using ethnographic techniques to plan Student Study Space", Technical Services Quarterly, Vol. 27 No. 4, pp. 347363, available at: https://doi.org/10.1080/07317131003766009

Holder, S. and Lange, J. (2014), "Looking and listening: A mixed-methods study of space use and user satisfaction", Evidence Based Library and Information Practice, Vol. 9 No. 3, pp. 4-27, available at: http://dx.doi.org/10.18438/B8303T

İmamoğlu, Ç. and Gürel, M. Ö. (2016), “'Good fences make good neighbors': Territorial dividers increase user satisfaction and efficiency in library study spaces", The Journal of Academic Librarianship, Vol. 42 No. 1, pp. 65-73, available at: https://doi.org/10.1016/j.acalib.2015.10.009

Kemp, K. and Bednarz, S.W. (2011), "Understanding and nurturing spatial literacy", Procedia - Social and Behavioral Sciences, Vol. 21, pp. 18-23, available at: https://doi.org/10.1016/j.sbspro.2011.07.004 
Khoo, M.J., Rozaklis, L., Hall, C., and Kusunoki, D. (2016), “'A really nice spot”: Evaluating place, space, and technology in academic libraries", College \& Research Libraries, Vol. 77 No. 1, pp. 51-70, available at: https://doi.org/10.5860/crl.77.1.51

Leckie, G., Given, L., and Buschman, J. (2010) Critical Theory for Library and Information Science: Exploring the Social from Across the Disciplines. Libraries Unlimited, CA.

Lefebvre, Henri; translated by Donald Nicholson-Smith (1991) The production of space. Blackwell

Lux, V., Snyder, R.J., and Boff, C. (2016), "Why users come to the library: A case study of library and non-library units", The Journal of Academic Librarianship, Vol. 42 No. 2, pp. 109-117, available at: https://doi.org/10.1016/j.acalib.2016.01.004

Mandel, L.H. (2010), "Toward an understanding of library patron wayfinding: Observing patrons' entry routes in a public library", Library and Information Science Research, Vol. 32 No. 2, pp. 116-130, available at: https://doi.org/10.1016/j.lisr.2009.12.004

Maxwell, J. (2004), “Using Qualitative Methods for Causal Explanations”, Field Methods, Vol. 16 No. 3, pp. 243-264, available at: https://doi.org/10.1177/1525822X04266831

May, F. and Swabey, A. (2015), "Using and experiencing the academic library: A multisite observational study of space and place", College \& Research Libraries, Vol. 76 No. 6, pp. 771-795, available at: https://doi.org/10.5860/crl.76.6.771.

Mills, K. (2016), Literacy theories for the digital age: social, critical, multimodal, spatial, material and sensory lenses, Multilingual Matters, Bristol.

Montgomery, S.E. (2014), "Library space assessment: User learning behaviors in the library", The Journal of Academic Librarianship, Vol. 40 No. 1, pp. 70-75, available at: https://doi.org/10.1016/j.acalib.2013.11.003

Newcomer, N.L., Lindahl, D., and Harriman, S.A. (2016), "Picture the music: performing arts library planning with photo elicitation", Music Reference Services Quarterly, Vol. 19 No. 1, pp. 18-62, available at: https://doi.org/10.1080/10588167.2015.1130575

Princeton Theological Seminary Library (2014), Library utilization study: first year in the new building final report, Princeton University, Princeton, NJ. 
Ridenour, C.S., and Newman, I. (2008), Mixed methods research: exploring the interactive continuum, $2^{\text {nd }}$ edn, Southern Illinois University Press, Carbondale.

Steinberg, S.L. and Steinberg, S.J. (2015), Gis research methods: incorporating spatial perspectives, Esri Press, California.

Taylor, S.J., Bogdan, R., and DeVault, M. (2016), Introduction to qualitative research methods: a guidebook and resource, $4^{\text {th }}$ edn, Wiley, New Jersey.

Thompson, S. (2015), "Using mobile technology to observe student study behaviors and track library space usage", Journal of Access Services, Vol. 12 No. 1-2, pp. 1-13, available at: https://doi.org/10.1080/15367967.2015.972754

Treadwell, J., Binder A. and Tagge, N. (2012), "Seeing ourselves as others see us: Library spaces through student eyes", in Duke, L.M. and Asher, A.D. (Eds.), College Libraries and student culture: what we know, American Library Association, Chicago, IL, pp. 127-142.

Turner, A., Welch, B., and Reynolds, S. (2013), "Learning spaces in academic libraries A review of the evolving trends", Australian Academic \& Research Libraries, Vol. 44 No. 4, pp. 226-234, available at: http://dx.doi.org/10.1080/00048623.2013.857383

Webb, K.M., Schaller, M.A., and Hunley, S.A. (2008), "Measuring library space use and preferences: Charting a path toward increased engagement", Portal: Libraries and the Academy, Vol. 8 No. 4, pp. 407-422, available at: http://ecommons.udayton.edu/roesch_fac/3

Xia, J. (2005), "Visualizing occupancy of library study space with GIS maps", New Library World, Vol. 106 No. 5/6, pp. 219-233 available at: https://doi.org/10.1108/03074800510595832

Yoo-Lee, E., Heon Lee, T., and Velez, L. (2013), "Planning library spaces and services for millennials: An evidence-based approach", Library Management, Vol. 34 No. 6/7, pp. 498-511, available at: https://doi.org/10.1108/LM-08-2012-0049 